\title{
A MICROSTRUCTURAL INTERPRETATION OF THE FLUENCE AND TEMPERATURE DEPENDENCE OF THE MECHANICAL PROPERTIES OF IRRADIATED AISI 316
}

G. D. Johnson, F. A. Garner,

H. R. Brager and R. L. Fish

April 17, 1980
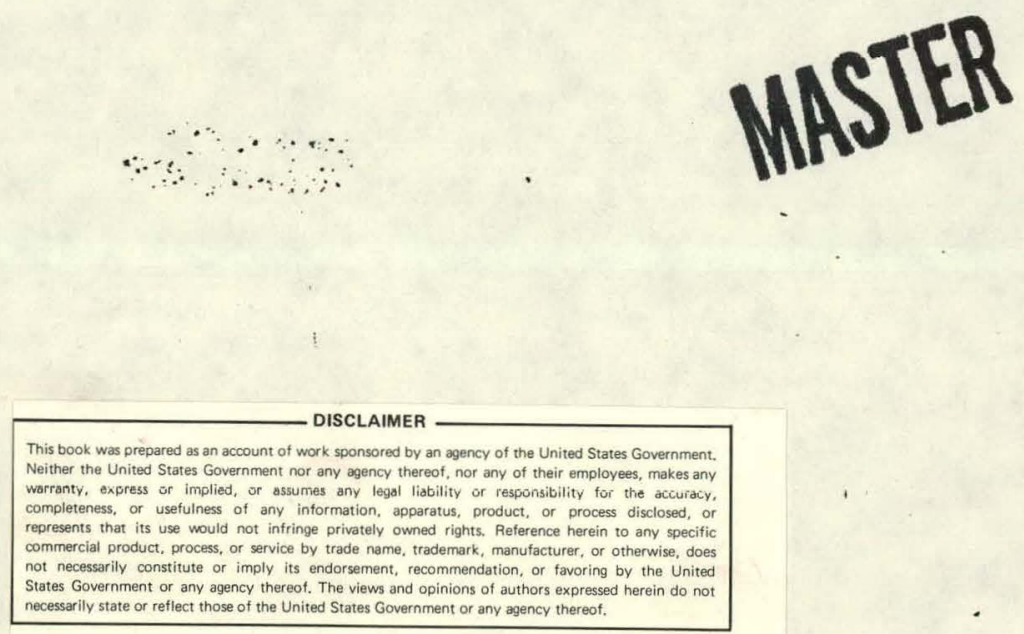

To be presented at the 10th International Symposium on Effects of Radiation on Materials on June 3-5, 1980 in Savannah, GA.

\section{HAMFORD ERGIMERR!HG DEVFLOPMCHT LABORATORY}

Operatad by Yiestimzlous? Haniord Comorny, a subsidiary of Westinghouse Elactuc Coroustion, uned the Department of

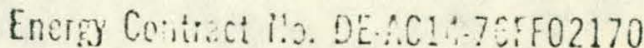

\section{COPYAGH PULSE ROHCE}

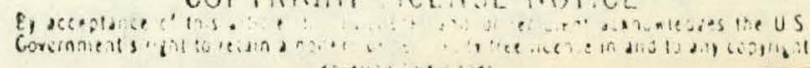




\section{DISCLAIMER}

This report was prepared as an account of work sponsored by an agency of the United States Government. Neither the United States Government nor any agency Thereof, nor any of their employees, makes any warranty, express or implied, or assumes any legal liability or responsibility for the accuracy, completeness, or usefulness of any information, apparatus, product, or process disclosed, or represents that its use would not infringe privately owned rights. Reference herein to any specific commercial product, process, or service by trade name, trademark, manufacturer, or otherwise does not necessarily constitute or imply its endorsement, recommendation, or favoring by the United States Government or any agency thereof. The views and opinions of authors expressed herein do not necessarily state or reflect those of the United States Government or any agency thereof. 


\section{DISCLAIMER}

Portions of this document may be illegible in electronic image products. Images are produced from the best available original document. 


\section{A MICROSTRUCTURAL INTERPRETATION OF THE FLUENCE AND TEMPERATURE DEPENDENCE OF THE MECHANICAL PROPERTIES OF IRRADIATED AISI 316}

G. D. Johnson, F. A. Garner, H. R. Brager and R. L. Fish

\section{ABSTRACT}

The effects of neutron irradiation on the mechanical properties of annealed and 20\% cold-worked AISI 316 irradiated in EBR-II were determined for the temperature regime of 370 to $760^{\circ} \mathrm{C}$ for fluences up to $8.4 \times 10^{22}$ $\mathrm{n} / \mathrm{Cm}^{2}$ ( $\left.\mathrm{E}>0.1 \mathrm{MeV}\right)$. At irradiation temperatures below about $500^{\circ} \mathrm{C}$, both annealed and cold-worked material exhibit a substantial increase in the flow stress with increasing fluence. Furthermore, both materials eventually exhibit the same flow stress, which is independent of fluence. At temperatures in the range of 538 to $650^{\circ} \mathrm{C}$, the cold-worked material exhibits a softening with eventual saturation of the flow stress with increasing fluence. Annealed AISI 316 in this temperature regime exhibits hardening and at a fluence of 2 to $3 \times 10^{22} \mathrm{n} / \mathrm{cm}^{2}(E>0.1 \mathrm{McV})$ reaches the same value of flow stress as the cold-worked material.

These observations are explained in terms of the fluence and temperature dependence of the irradiation-induced microstructure. It has been shown that AISI 316 proceeds toward an equilibrium dislocation and Frank lonp microstructure that is independent of the initial microstructure. There is a signifirant hardening that arises from the precipitation of small $\gamma^{\prime}$ and G-phase particles, both of which are formed only during irradiation and develop at temperatures less than about $550^{\circ} \mathrm{C}$. Voids and Frank loops also produce hardening and exhibit a strong temperature dependence. Very good agreement 
between the observed data and calculated strengths was obtained for both SA and CW AISI 316 through the use of simple hardening expressions for each type of microstructural defect. Extrapolation of these results to other reactor systems will lead to slightly different results because of flux and spectral effects on microstructural development.

KEY WORDS: irradiation effects, stainless steel, microstructure, mechanical properties, correlations 


\section{INTRODUCTION}

In principle, it should be possible to relate changes in mechanical properties that develop in metals during irradiation to the induced microstructural alterations. This requires detailed knowledge of the relevant microstructural components, their densities and their action with respect to the property change of interest. With the exception of thin foil irradiation with electrons in a high voltage microscope, it is generally impossible to observe the development of microstructural components during irradiation. After the irradiation has ceased, processes such as dislocation climb and enhanced surface or bulk diffusivity decrease sharply or terminate. : Some ongoing processes such as solute segregation may actually reverse, and some short-lived components such as vacancy loops may be annealed. In the most pessimistic sense, then, the use of postirradiation microstructure in modeling effects of radiation-induced changes is best confined to the description of ex-reactor properties. It does appear; however, that the major components (dislocations, loops, voids and precipitates) that develop at irradiation temperatures in the range of 300 to $700^{\circ} \mathrm{C}$ are relatively stable during reactor cool-down, extraction from the reactor, subsequent storage and handling.

Prior to describing the application of postirradiation microstructural data to modeling of in-reactor behavior, it is best to demonstrate that such efforts can be successful in predicting ex-reactor properties. The best choice for an initial effort is the yield stress, since the processes involved are of short duration and involve primarily the mechanical rather than the chemical aspects of various components. Yield stress measurements also involve only the influence of the radiation-induced microstructure and not that produced by the ex-reactor deformation. 
As our understanding of the microstructural evolution of AISI 316 has evolved, a number of attempts ${ }^{(1-3)}$ have been made to determine the relative contributions of each microstructural component to the hardening or softening of the material observed for a given set of irradiation conditions. These efforts have been hampered by incomplete or incorrect descriptions of the microstructure and some ambiguity concerning the exact nature of hardness models for each component.

Several recent developments now allow a potentially more successful description of yield stress as a function of microstructure. The examination of AISI 316 in the U.S. Breeder Reactor Program has yielded not only detailed yield stress data as a function of fluence, temperature and starting condition, but has also provided substantial insight on the nature of the microstructural and microchemical evolution in this alloy. In addition, it has been shown in the Breeder Program and elsewhere ${ }^{(4-7)}$ that the yield stress of this alloy saturates with continuing irradiation at a level which is primarily dependent on the irradiation temperature, but not the cold work level of the alloy. Figure 1 shows this saturation effect for irradiated $20 \% \mathrm{CW}$ AISI 316. (7) The convergence of the yield strength of solution annealed (SA) AISI $316^{(8)}$ with the yield strength of the $20 \%$ CW AISI 316 as a function of fluence is shown in Figure 2. This convergence is obvious at $650^{\circ} \mathrm{C}$ and is suggested at 427 and $538^{\circ} \mathrm{C}$. This convergence of the strengths of the two materials implies that the saturation "hardness" of the alloy is reached by more than one microstructural evolutionary path. This in turn allows for a better assessment to be made of the relative contribution of each microstructural component.

The following sections present first an overview of the microstructural evolution of this alloy, followed by an assessment of the various hardening models for each microstructural component, and the results of an attempt to reproduce these data without any adjustment of the assumed densities or 
hardening coefficients.

AN OVERVIEW OF THE MICROSTRUCTURAL EVOLUTION

It has been shown that the irradiation of AISI 316 leads to the initiation of two concurrent and interactive evolutions, one involving the development of various types of dislocations and voids and another involving precipitates! (9-11\&19) This latter evolution leads to an extensive repartitioning of various elements between the various phases. Development of the dislocation and loop microstructure (and to a lesser extent, voids) proceeds toward a saturation state, comprised of number densities and component identities, which are independent of starting microstructure. The network dislocation density at saturation is apparently independent also of temperature and displacement rate, while the saturation densities of voids and dislocation loops are quite dependent on both variables. The densities of these components are also sensitive to the stress state, (12) however, particularly at low fluences, while the network saturation density is not. (19)

Precipitate-related evolution also appears to proceed toward a saturation state at a more sluggish pace than that of other components of the microstructure. This evolution has been labeled as "microchemical" in order to describe the heterogeneity and small dimensions over which the evolution occurs. In general, two categories of precipitates evolve. The first of these are low temperatures phases ( $\gamma^{\prime}$, G-phase) which exist at relatively high densities and small sizes only in the presence of irradiation and which dissolve slowly when irradiation ceases and the temperature is maintained. The second category is comprised of the normal metastable phases such as Laves and various carbides. These phases usually exist at lower densities and larger sizes at higher temperatures. While the phases which develop in the first category are naturally rich in nickel and silicon, continued irradiation of the phases in the second 
category leads to their progressive enrichment in those same elements. The majority of the mechanical and dimensional property changes of interest have been shown to be related to the details of the microchemical evolutionary path. (11) In general, however, the rate and type of precipitation, particularly at temperatures below $550^{\circ} \mathrm{C}$, can be quite variable and is not always easily predicted.

\section{IRRADIATION HARDENING}

It is common to describe the effects of neutron irradiation hardening with models that account for the interaction of various defects with moving dislocations. (13) Barriers which resist the motion of dislocations have been classified as either long range (LR) or short range (SR). Long range forces are due to the interaction of moving dislocations with the dislocation network of the material. Obstacles lying in the slip plane of the moving dislocation produce short range forces when the dislocation is in close proximity to the obstacles. The increase in the shear stress, $\Delta \tau$, is given by:

$$
\Delta \tau=\Delta \tau_{L R}+\Delta \tau_{S R}
$$

In the present case, $\Delta \tau_{S R}$ is due to the combined effects produced by Frank loops, voids and precipitates. The contribution due to Frank loops $(14)$ is given by:

$$
\Delta \tau_{F L}=\frac{\dot{G} b \sqrt{N d}}{\beta_{F L}}
$$

where $G$ is the shear modulus, $b$ is the Burgers vector, $N$ is the density of loops, $d$ is the average loop diameter, and $\beta_{F L}$ is a constant in the range of 2 to 4 . The contribution from voids $(15)$ and precipitates $(16)$ can be described by:

$$
\Delta \tau_{v} \text { or } \Delta \tau_{p}=\frac{G b \sqrt{N d}}{\beta_{v, p}}
$$

where $\beta_{v, p} \approx 1$. 
The long range term is given as:

$$
\Delta \tau_{L R}=\alpha G b \sqrt{\rho} \text {, }
$$

where $\rho$ is the network dislocation density and $\alpha$ is a constant in the range of 0.15 to $0.30 .(17)$

In computing the flow stress for the irradiated material, it is necessary to know how to account for the increment produced by each type of obstacle. Simple addition of barrier stresses gives:

$$
\Delta \tau=\Delta \tau_{L R}+\Delta \tau_{S R}=\Delta \tau_{L R}+\Delta \tau_{F L}+\Delta \tau_{V}+\Delta \tau_{p}
$$

Little physical justification can be attached to this method, although it has been used by many investigators.

A second method, originally based on two types of short range obstacles is :

$$
\Delta \tau_{S R}=\left(\Delta \tau_{F L}{ }^{2}+\Delta \tau_{v}{ }^{2}+\Delta \tau_{p}{ }^{2}\right)^{1 / 2}
$$

and:

$$
\Delta \tau=\Delta \tau_{L R}+\left(\Delta \tau_{F L}{ }^{2}+\Delta \tau_{v}{ }^{2}+\Delta \tau_{p}{ }^{2}\right)^{1 / 2}
$$

In the present work, both equation (5) (referred to as SUM) and equation (7) (referred to as root-mean-square, RMS) were used to calculate the increase in flow stress due to irradiation produced defects. Finally, in calculating the increment in the flow or yield stress, it is necessary to convert from shear stress to uniaxial stress, namely $\Delta \sigma_{y}=\sqrt{3} \Delta$ t based on the Von Mises criterion. Thus, the yield strength of the irradiated steel, $\sigma_{i}$, is:

$$
\sigma_{i}=\sigma_{0}+\Delta \sigma_{y},
$$

where $\sigma_{0}$ is the intrinsic yield strength of the unirradiated steel and is assumed not to change during irradiation. 
DEFECT PARAMETERS

Calculations of the yield strength of irradiated AISI 376 requires a knowledge of the dislocation density, $\rho$, and the parameters $N$ and $d$ for the various defects; moreover, it is necessary to know how these parameters vary with temperature and fluence. The next sections discuss the correlations used for describing the density, size and hardening produced by these microstructural defects.

Network Dislocations

In the work of Brager, et al., (19) it was shown that the dislocation density in both CW and SA AISI 376 reaches a saturation value, independent of temperature over a very wide range of about $6 \pm 3 \times 10^{10} \mathrm{~cm}^{-2}$. In the case of $20 \%$ CW AISI 316 , this represents a decrease from an initial value of about $3 \times 10^{11} \mathrm{~cm}^{-2}$, and for SA AISI 316, it represents a large increase from an initial value which is on the order of $10^{8}$ to $10^{9} \mathrm{~cm}^{-2}$.

The value of $\alpha$ in equation (4) was calculated from known yield strength values of unirradiated SA and CW AISI 316, (20) and from the known values of $\rho$. The value of $\alpha$ obtained was 0.2 , which is within the range quoted in Reference 17.

Since the dislocation density in CW AISI 316 decreases quickly at elevated temperatures, it was necessary to evaluate the initial value of $\rho$ as a function of temperature in order to provide a starting point for the description of $\rho=f(\phi t)$ at various temperatures. Again, unirradiated yield strength values were used to estimate $\rho=f(T)$. Yield strength data of unirradiated $S A$ and $20 \%$ CW AISI 316 are shown in Figure 3 as a function of temperature. Using the expression:

$$
\rho=\left(\frac{{ }^{\tau} \mathrm{CW}-{ }^{\top} S A}{U .2 G b}\right)^{2}
$$


values of $\rho$ were computed as a function of temperature. Temperature dependent values of $G$ were obtained from Reference 21 . The Burgers vector, $b$, was taken as $2.5 \times 10^{-8} \mathrm{~cm}$. An equation was developed which describes the temperature dependence of the initial dislocation density of $20 \%$ CW AISI 316.

$$
{ }^{\circ} \mathrm{CW}(T)=[4-0.0017 \exp (T / 100)] \times 10^{11},
$$

where $T$ is in ${ }^{\circ} \mathrm{C}$ and $\rho_{\mathrm{eW}}$ is in $\mathrm{cm}^{-2}$. This expression was used to calculate the yield strength of $20 \% \mathrm{CW}$ AISI 316 as a function of temperature. The result is shown in Figure 3.

The value of ${ }^{\rho} \mathrm{CW}$ as a function of fluence is given by:

$$
{ }^{\circ} \mathrm{CW}=6 \times 10^{10 \phi t^{-0.7}} \text {, }
$$

for values of $\phi t>0.1$, and with the condition that the calculated value of ${ }^{\rho} \mathrm{CW}$ is never less than $6 \times 10^{10} \mathrm{n} / \mathrm{cm}^{2}$; $\phi$ t has units of $10^{22} \mathrm{n} / \mathrm{cm}^{2}$. Thus, the calculated yield strength increment for $20 \%$ CW AISI 316 is given by:

$$
\Delta \sigma=0.35 G b\left(\sqrt{\rho_{C W}}-\sqrt{\rho_{C W}}\right) \text {. }
$$

This equation produces a negative value of $\Delta \sigma$ since the dislocation density is decreasing relative to that of the unirradiated condition.

For the solution annealed AISI 316 the increase in $\rho$ is given by:

$$
\rho_{S A}=1.9 \times 10^{10} \phi t^{1.7},
$$

for values of $\phi t>0.1$ and with the condition that the maximum value of $\rho_{S A}$ is $6 \times 10^{10} \mathrm{~cm}^{-2}$.

\section{Frank Loops}

The hardening due to Frank loops is given by equation (2). Instead of trying to describe $N$ and $d$ as functions of temperature and fluence, it is only necessary to relate the product of these two as $f(T, \phi t)$. This was done for both the SA and CW AISI 316 data, $(19,22)$ and the results are shown in Figure 4. 
Data for both $\mathrm{CW}$ and SA AISI 316 exhibit the same temperature dependence at saturation and show only slight dependence on fluence. The hardening produced by the Frank loops saturates earlier at lower temperatures and is essentially independent of fluence beyond a value of $2 \times 10^{22} \mathrm{n} / \mathrm{cm}^{2}$. The temperature and fluence dependence of the Frank loop hardening is given by:

$$
\begin{gathered}
\log _{10} \sqrt{N d_{F L}}=0.39+\frac{\operatorname{TANH}(\phi t+A)}{2}+\frac{2834.3}{(T+273.16)} \\
A=-\frac{\operatorname{TANH}\left(\frac{T-465}{2}\right)}{2},
\end{gathered}
$$

where $N$ is the number density $\left(\mathrm{cm}^{-3}\right), d$ is the average loop diameter $(\mathrm{cm}), \phi t$ is the neutron fluence $\left(10^{22} \mathrm{n} / \mathrm{cm}^{2}\right)$, and $T$ is the temperature $\left({ }^{\circ} \mathrm{C}\right)$. A value of $\beta_{F L}=3$ was used in conjunction with equation (2).

Cavities: Cold Worked AISI 316

As with the Frank loops, it was only necessary to evaluate (Nd) $1 / 2$ as a function of $T$ and $\phi t$. Helium bubbles found in AISI 316 irradiated in breeder reactors are at too low densities and too small sizes to significantly affect the yield stress. Void data for CW AISI 316 are shown in Figure 5 . The correlation obtained for void hardening in CW AISI 316 was:

$$
\log _{10} \sqrt{N d_{v}}=0.47 \phi t^{0.49}+\frac{2446}{(T+273.16)} \cdot
$$

Since the voids begin to coalesce eventually and the average diameter increases with $\phi t$, the hardening tends toward saturation. This behavior is indicated by the dashed line for the higher fluence material. Thus, the value of $\sqrt{\mathrm{Nd}}$ given by equation (16) was subjected to maximum limit of:

$$
(\sqrt{\mathrm{Nd}})_{\max }=38,000+45,000 \mathrm{TANH}\left(\frac{\phi \mathrm{t}-1}{2.6}\right)
$$


Due to data scatter, it was somewhat difficult to determine the proper value of the coefficient of the second term in equation (16). Data for cold worked M316 ${ }^{(23)}$ derived from fuel pins irradiated in DFR were used as a basis for determining the slope. These data are shown in Figure 6 and the slope represented by the line in the figure was used in equation (16). The data shown in Figure 6 are for fluences on the order of $7 \times 10^{22} \mathrm{n} / \mathrm{cm}^{2}$, and again, the data indicate a saturation for the value of $(\mathrm{Nd})^{1 / 2}$.

Voids - Solution Annealed AISI 316

It was determined that the temperature dependence of void hardening in SA AISI 316 was essentially the same as that for CW AISI 316. The only difference between the two conditions is the rate at. which the hardening develops. For SA AISI 316:

$$
\log _{10} \sqrt{N d_{v}}=1.17+\frac{\operatorname{TANH}\left(\frac{\phi t-2.7}{2}\right)}{3.75}+\frac{2446}{(T+273.16)}
$$

and the maximum value of $(N d)^{1 / 2}$ is:

$$
(\sqrt{\text { Nd }})_{\max }=48,000 \phi t^{0.28}
$$

The data (22) and calculated lines for several fluences are shown in Figure 7.

\section{Precipitates}

For the precipitates described earlier, the following expressions were used:

SA AISI 316: $\quad \sqrt{N d_{p}}=[5,000+5,000 \operatorname{TANH}(\phi t-1.8)] \exp \left[\frac{1633}{T+273.16}\right]$

CW AISI 316: $\sqrt{\mathrm{Nd}}=44,000+44,000$ TANH $(\phi t-1.8)$

Equations (20) and (21) were limited to irradiation temperatures $\leq 500^{\circ} \mathrm{C}$.

\section{RE.SULTS}

As described earlier, the increase in yield strength was evaluated by two approaches, labeled SUM and RMS. Values for $\sigma_{0}$ were obtained from References 8 and 20. Calculations were made for irradiation temperatures of $370,427,538$ 
and $650^{\circ} \mathrm{C}$ for both alloy conditions. Figures 8 and 9 show the results for SA AISI 316 and 20\% CW AISI 316 respectively. For each temperature, curves are given for the contribution due to each microstructural defect and for the total yield stress based on the two approaches (SUM and RMS). For SA AISI 316 at $370-538^{\circ} \mathrm{C}$, the estimated saturation value of the yield stress was based on the $20 \%$ CW AISI 316 data. ${ }^{(7)}$

There were no yield stress data for SA AISI 316 irradiated at $370^{\circ} \mathrm{C}$, but European data show convergence of cold worked and annealed materials at low temperatures. (6) Based on the observations for $T=427^{\circ} \mathrm{C}$, it is expected that the strength of the SA AISI 316 approaches that of the CW AISI 316. Thus, results of calculations are provided for comparison to this saturation value. At temperatures of 370 and $427^{\circ} \mathrm{C}$, all defects produce a noticeable hardening. At 538 and $650^{\circ} \mathrm{C}$, there is no hardening term due to precipitates and the major hardening source is the network dislocations. At the lower temperatures, the SUM curves overestimate the strength and the RMS curves underpredict the strength. At the higher temperatures there is little difference between the two approaches, since the short range contributions are small. It should be noted that the overall agreement between the RMS curve and the data trends is quite good. Remember that $\beta_{F L}=3$ was used for the Frank Loops while it was noted that $\beta_{F L}$ could be in the range of 2 to 4 . If $\beta_{F L}=2$ were used, the RMS and SUM curves would be raised slightly, producing a somewhat better agreement between the RMS and observed values.

Results of the calculations for CW AISI 316 (Figure 9 ) show trends similar to SA AISI 316. At the lower temperatures, the SUM approach tends to overpredict at high fluences, while the RMS curve underpredicts the data. At the higher temperatures the two approaches yielded about the same value. At 370 and $427^{\circ} \mathrm{C}$, the agreement at lower fluences could be better. This mismatch between calculated and observed values arises because of uncertainties 
associated with the rate of relaxation of the dislocation density and the rate of development of the precipitates. Currently, the limits of the data do not permit a detailed description of these processes.

\section{DISCUSSION}

It should be noted that the temperature dependency of the yield stress arises primarily from the temperature dependence of the densities of Frank loops, voids and precipitates, the latter not having been included by previous investigators. It is important to note, however, that the temperature dependence at saturation does not arise from the network of dislocations as has been previously modeled. (3) The temperature-sensitive components are also sensitive to the neutron flux level with their densities and rate of formation increasing with displacement rate. (24) This sensitivity has been observed in the French irradiation programs, ${ }^{(5)}$ as shown in Figure 10 . The yield stress of SA AISI 316 irradiated in Rapsodie saturates at a lower value than when irradiated in Phenix. The dose rate in Phenix is about a factor of two higher than in Rapsodie. This combination of a flux and temperature dependence was found to exist in the yield stress for the fuel: pin cladding. Saturation yield stress data from the French program ${ }^{(5)}$ are plotted in Figure 11 and appear to exhibit the same type of rate-related temperature shift characteristic of the swelling phenomenon. This implies that correlations developed in fast reactor environments may need to be reformulated to include flux and spectral dependencies prior to application to higher flux powergenerating reactors or to magnetic fusion devices which operate at other displacement rates and time-dependent flux histories.

The fairly large role played by voids in the determination of yield stress indicates that application of a yield stress correlation to fusion environments must anticipate additional hardening due to the large number of cavities that develop at high helium/displacement ratios. 
Justification of the assumption made in this work that the microstructural contributions are merely added to the intrinsic yield stress of the matrix, and that the matrix contribution does not change during irradiation is not obvious. The known microchemical evolution in this steel results in a substantial alteration of the matrix composition, including the removal of the major solutes (carbon and silicon) and major changes in the nickel, manganese and molybdenum concentrations. There is no evidence of this change discernible in the yield stress data or in the microstructural modeling, and it may well be that any such change is already implicitly modeled in the precipitate contributions to hardening. At low temperature the precipitates form at essentially their final composition, rather than evolve slowly by the infiltration-exchange process which dominates at higher temperatures. (10) In the higher temperature range the precipitates are generally larger and fewer in number and contribute very little to hardening.

The detailed modeling of the transient period employed data on phase development that may not aiways apply to the alloy in every starting condition or irradiation history. (9) The saturation level of precipitate hardening will be essentially unaffected by this consideration, however. If the specimen is slressed during irradiation the contribution from Frank loops will increase at a faster rate $(12,25)$ but the eventual hardness contribution from loops will be identical to that of the unstressed case. Short-term mechanical property measurements (transient burst tests) have shown that the mechanical behavior of stressed and unstresses specimens is essentially identical. (26)

\section{CUNCLUSIUNS}

Effects of neutron irradiation on the strength of AISI 316 have been characterized in terms of the evolution of the variaus microstructural defects present in the steel for any given temperature and exposure. The change in strength of irradiated solution annealed and $20 \%$ cold worked AISI 316 can be 
described with the RMS model for the relative hardening produced by dislocations, Frank loops, voids and precipitates. It appears that the hardening parameters for Frank loops may be at the low end of its normally assumed range indicating a harder barrier for dislocation motion. Both conditions of this alloy eventually exhibit the same strength at high fluence for irradiation temperatures of 370 to $650^{\circ} \mathrm{C}$. Since the correlations were developed in terms of the hardening produced by the various defects, application of these correlations to other reactors will result in predictions that are different from that predicted for EBR-II irradiation because of the flux and spectral dependencies of the various microstructural components. With appropriate low fluence microstructural data from the nonbreeder environment, it will be possible to estimate the trend of the flow stress with temperature and fluence, since all of the major microstructural components have been included in the yield stress correlation. 


\section{REFERENCES}

1. J. J. Holmes, R. E. Robbins, J. L. Brimhall and B. Mastel, Acta Met., 16, 955 (1968).

2. J. R. Matthews, Contemp. Phys., 18, 571 (1977).

3. G. R. Odette and D. Frey, J. Nucl. Mat., $85 \& 86,817$ (1979).

4. J. J. Holmes and J. L. Straalsund, Proceedings of the International Conference on Radiation Effects in Breeder Reactor Structural Materials, AIME (1977), pp. 53-63.

5. J. M. Dupouy, J. Erler and R. Huillery, ibid, Ref. 4, pp 83-93.

6. K. Q. Bagley, J. W. Barnaby and A. S. Fraser, BNES Conference on Irradiation Embrittlement and Creep on Fuel Cladding and Core Components (1972), pp. 143-153.

7. R. L. Fish, N. S. Cannon and G. L. Wire, ASTM ST 683, pp. 450-465.

8. R. L. Fish and J. J. Ho.lmes, J. Nucl, Mat., 46; 113 (1973).

9. H. R. Brager and F. A. Garner, ASTM STP 683, pp. 207-232.

10. H. R. Brager and F. A. Garner, "Analys is of Radiation-Induced Microchemical Evolution in 300 Series Stainless Steel," 109th AIME Annual Meeting (February 1980), Las Vegas, Nevada.

11. H. R. Brager and F. A. Garner, 10th International Symposium on Effects of Radiation on Materials, ASTM (June 1980).

12. H. R. Rrager, F. A. Garner and G. L. Guthrie, J. Nucl. Mat., 66, $301(1977)$.

13. A. L. Bement, Jr., Proceedings, 2nd International Conference on the Strength of Metals and Alloys, ASM: (1970), pp. 693-128.

14. R. L. Fleischer, Acta Met., 10, 835 (1962).

15. P. Coulomb, Acta Met., I, 556 (1959).

16. E. Orowan, "Internal Stresses in Metals and Alloys", Inst. of Met., Londond (1948), p. 451. 
17. J. D. Embury, in Strengthening Methods in Crystals, A. Kelly and R. B. Nicholson (eds), J. Wiley \& Sons, New York (1971), Chapter 6.

18. T. J. Koppenal and D. Kuhlmann-Wilsdorf, Applied Phys. Letters, 4 , No. $3,59(1964)$.

19. H. R. Brager, F. A. Garner, E. R. Gilbert, J. Flinn and W. G. Wolfer, Proceedings of International Conference on Radiation Effects in Breeder. Reactor Structural Materials, AIME (1977), pp. 727-755.

20. M. M. Paxton, HEDL-TME 74-11 (1974).

21. Nuclear Systems Materials Handbook, TID 26666, Section 4, Code 2112.

22. H. R. Brager and J. L. Straalsund, J. Nucl. Mat., 46, 134 (1973).

23. C. Brown, J. K. Butler and E. J. Fulton, Proceedings of the International Conference on Irradiation Behavior of Metallic Materials for Fast Reactor Core Components, Ajaccio, Corsica, June 1979, Paper D1.

24. J. E. Westmoreland, J. A. Sprague, F. A. Smidt, Jr., and P. R. Malmberg, Radiation Effects, 26 , 1 (1975).

25. F. A. Garner, W. G. Wolfer and H. R. Brager, ASTM STP 683, pp. 160-183.

26. D. R. Duncan, ibid, Ref. 25, pp. 567-577. 


\section{FIGURE TITLES}

Figure 1: Yield Strength of 20\% CW Type 316 Stainless Steel After EBR-II Irradiation

Figure 2a: Yield Strength of Irradiated AISI 316 for a Test Temperature and Irradiation Temperature of $427^{\circ} \mathrm{C}$.

Figure 2b: Yield Strength of Irradiated AISI 316 for a Test Temperature and Irradiation Temperature of $538^{\circ} \mathrm{C}$.

Figure 2c: Yield Strength of Irradiated AISI 316 for a Test Temperature and Irradiation Temperature of $650^{\circ} \mathrm{C}$.

Figure 3: Yield Strength of Unirradiated AISI 316.

Figure 4: Parameter (Nd) ${ }^{1 / 2}$ Due to Frank Loops.

Figure 5: Parameter (Nd) ${ }^{1 / 2}$ Due to Voids in $20 \%$ CW AISI 316.

Figure 6: Parameter (Nd) ${ }^{\overline{7} / 2}$ Due to Voids in CW-M316 (UK data).

Figure 7: Parameter (Nd) ${ }^{1 / 2}$ Due to Voids in SA AISI 316.

Figure 8a: Calculated Yield Strengths for SA AISI 316 for a Test Temperature and Irradiation Temperature of $370^{\circ} \mathrm{C}$.

Figure 8b: Calculated Yield Strengths for SA AISI 316 for a Test Temperature and Irradiation Temperature of $427^{\circ} \mathrm{C}$.

Figure 8c: Calculated Yield Strengths for SA AISI 316 fir a Test Temperature and Irradiation Temperature of $538^{\circ} \mathrm{C}$.

Figure 8d: Calculated Yield Strengths for SA AIST 316 for a Test Temperature and Irradiation Temperature of $650^{\circ} \mathrm{C}$.

Figure 9a: Calculated Yield Strengths for 20\% CW AISI 316 for a Test Temperature and Irradiation Temperature of $370^{\circ} \mathrm{C}$.

Figure 9b: Calculated Yield Strengths for 20\% CW AISI 316 for a Test Temperature and Irradiation Temperature of $427^{\circ} \mathrm{C}$.

Figure 9c: Calculated Yield Strengths for 20\% CW AISI 316 for a Test Temperature and Irradiation Temperature of $538^{\circ} \mathrm{C}$.

Figure 9d: Calculated Yield Strengths for 20\% CW AISI 316 for a Test Temperature and Irradiation Temperature of $650^{\circ} \mathrm{C}$.

Figure 10: Comparison of the Yield Strength of SA 316 Irradiated in Phenix and Rapsodie $\left(T=400^{\circ} \mathrm{C}\right)$.

Figure 11: Temperature Shift of Saturation Yield Strength of SA 316 Irradiated in Phenix and Rapsodie. 


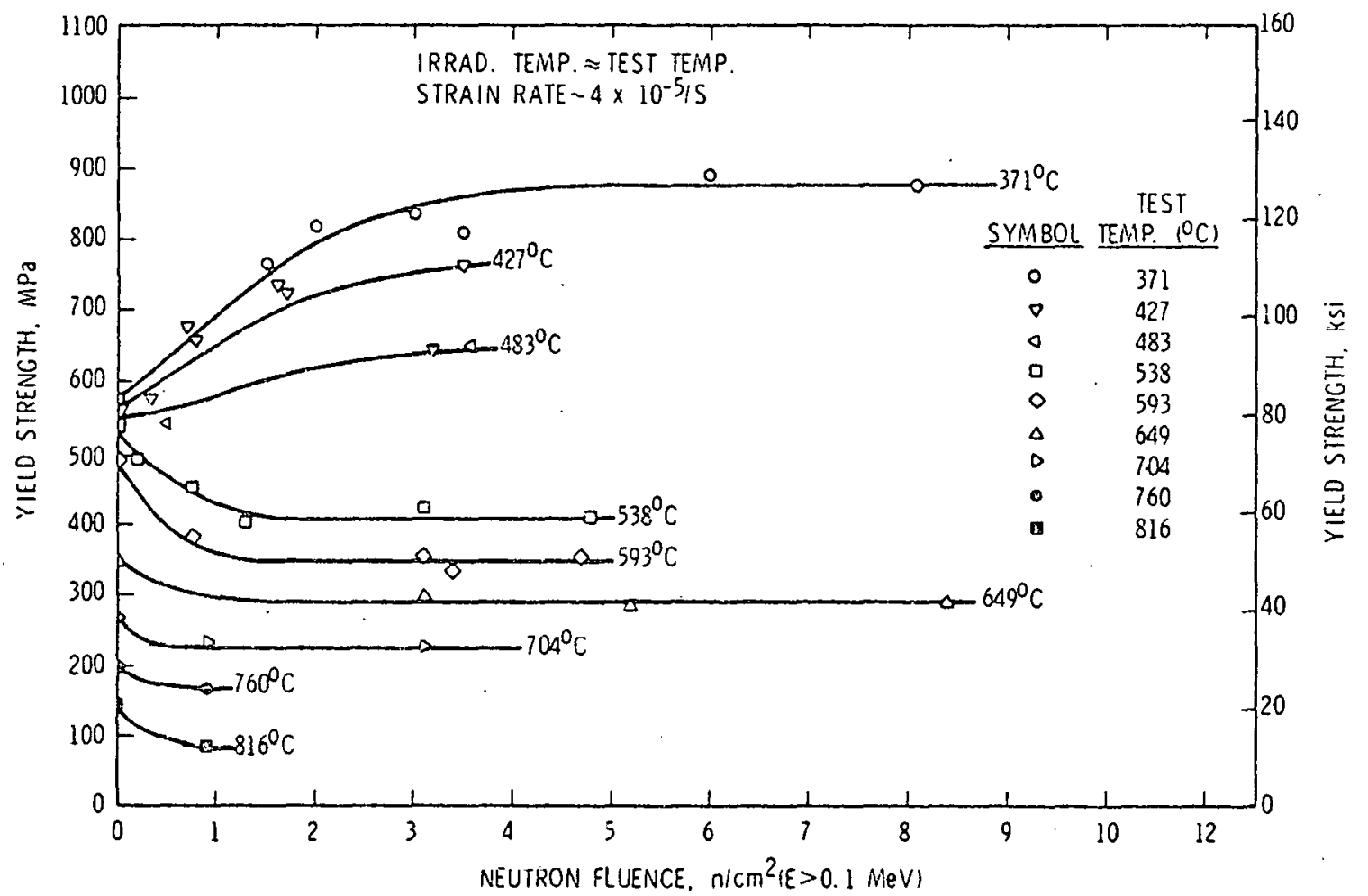

FIGURE 1: Yield Strength of 20\% CW Type 316 Stainless Steel After EBR-II Irradiation 


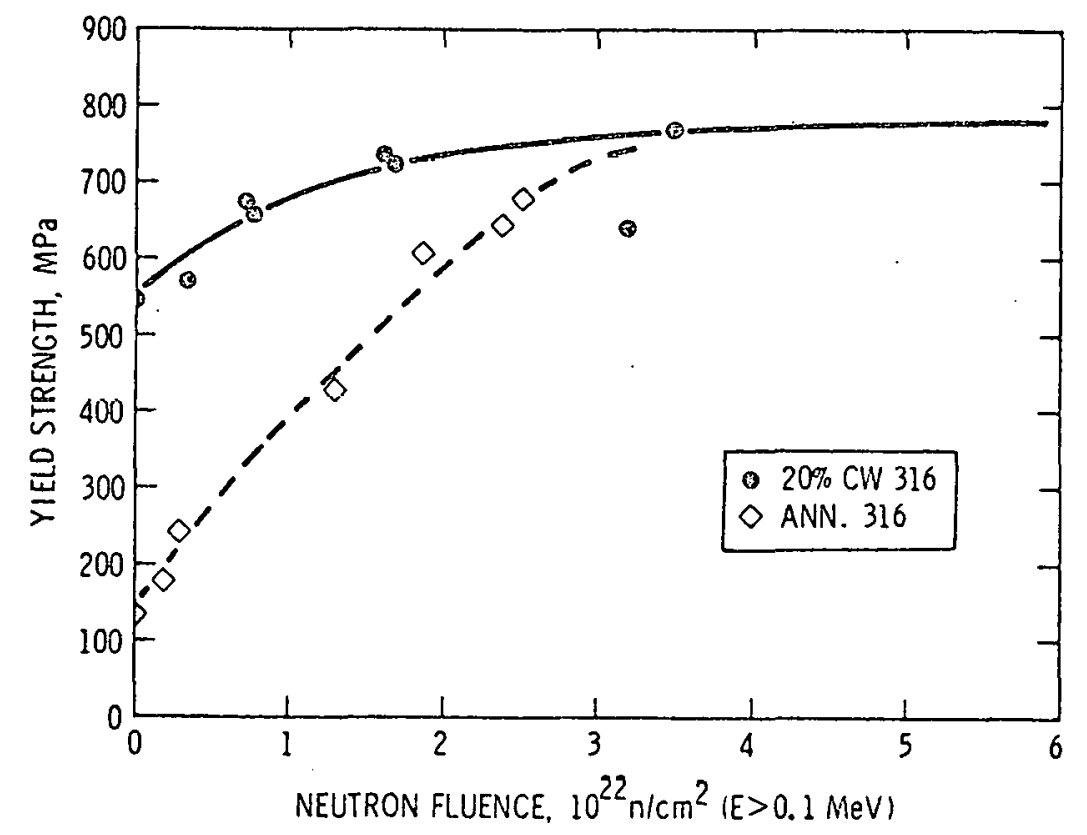

HEDL $8004-124.2$

FIGURE 2a: Yield Strength of Irradiated AISI 316 for a Test

Temperature and Irradiation Temperature of $427^{\circ} \mathrm{C}$.

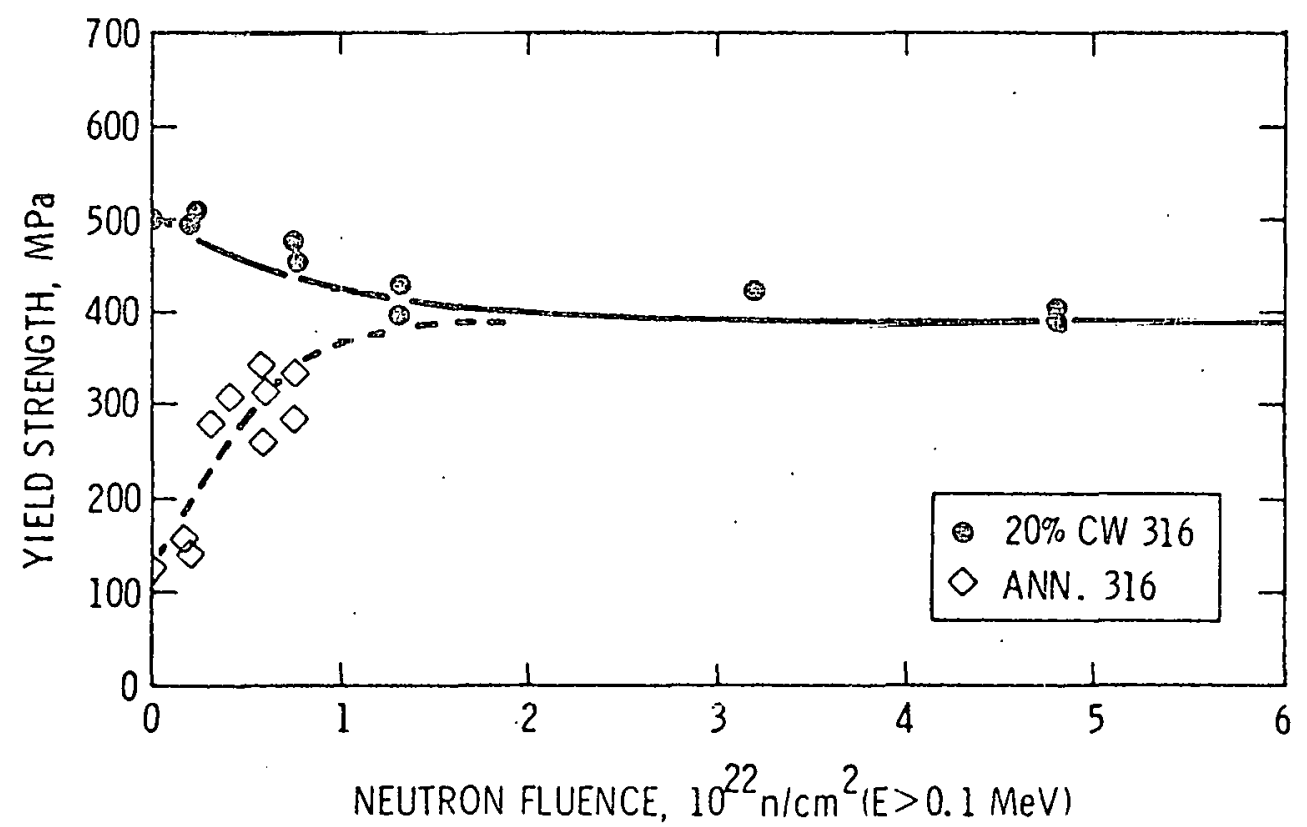

HEDL $8004-124.1$

FIGURE 2b: Yield Strength of Irradiated AISI 316 for a Test

Temperature and Irradiation Temperature of $539^{\circ} \mathrm{C}$. 


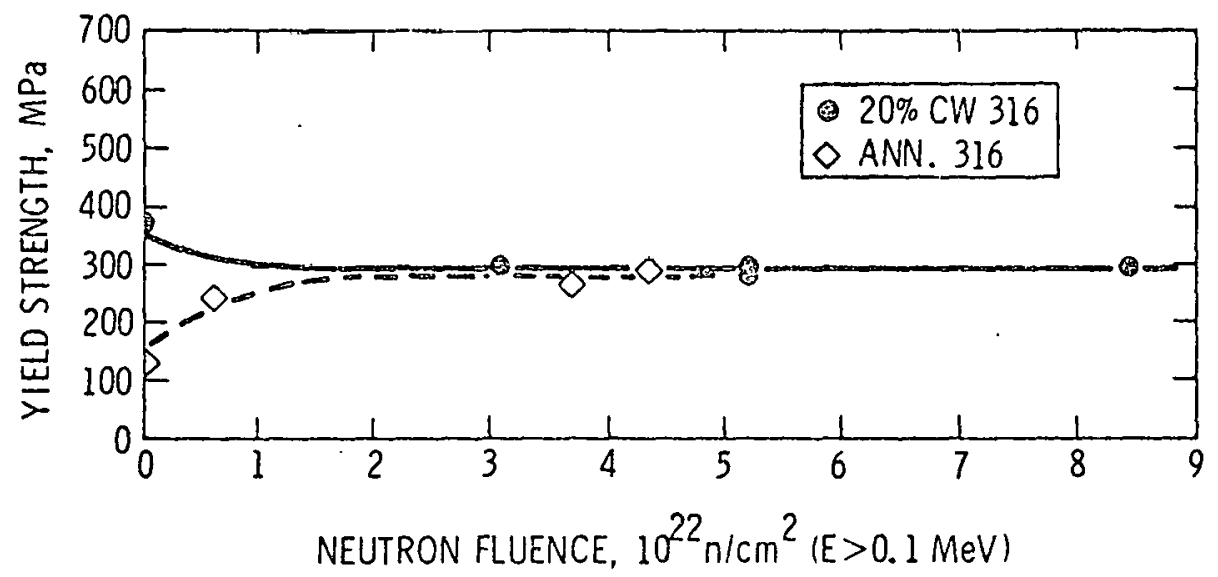

HEDL $8004-124.14$

FIGURE 2c: Yieid Strength of Irradiated AISI 376 for a Test
Temperature and Irradiation Temperature of $650^{\circ} \mathrm{C}$

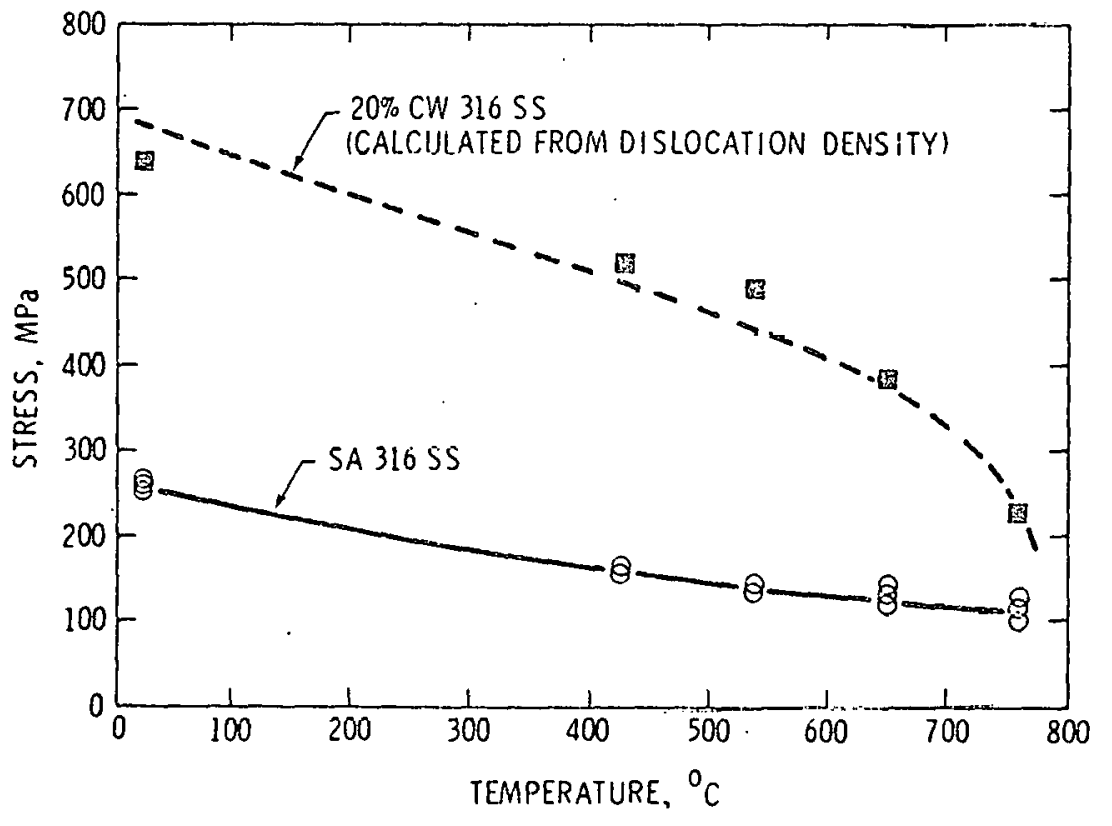

FICURE 3: Yield Strength of Unirradiated AISI 316 


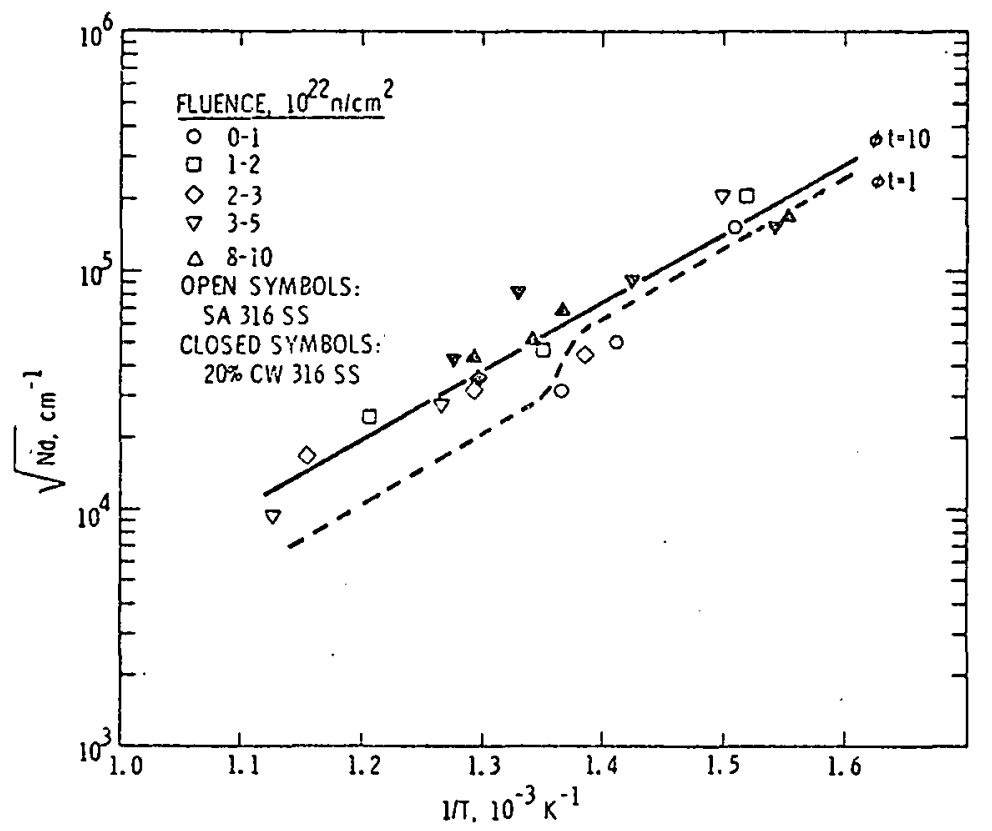

HEDL $2004-124.3$

FIGURE 4: Parameter (iNd) ${ }^{1 / 2}$ Due to Frank Loops

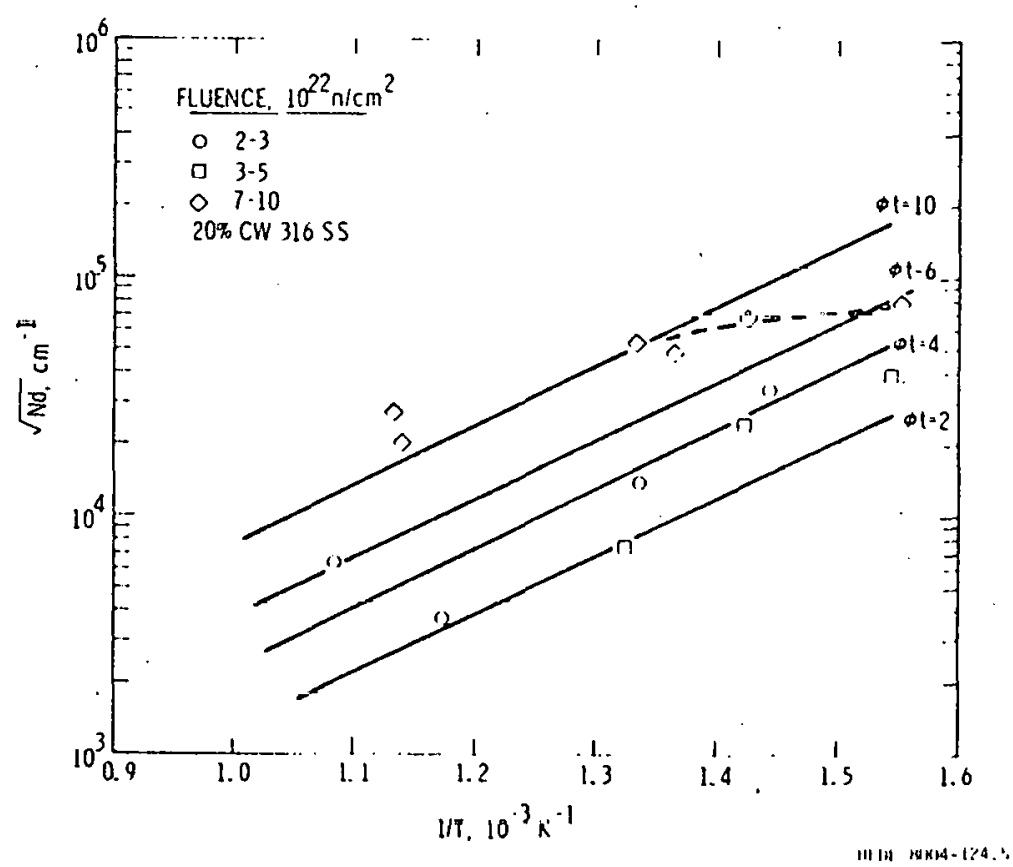

FIGURE 5: Parameter (Nd) $)^{1 / 2}$ Due to Voids in $20 \%$ CH MISI 316 


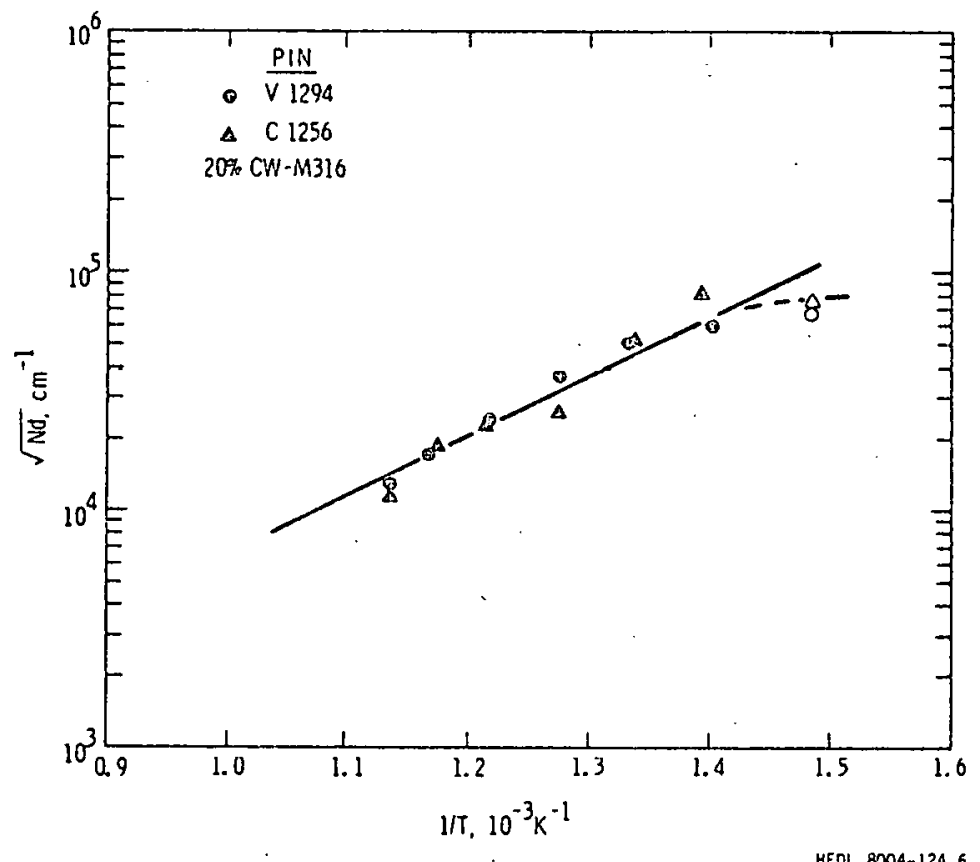

FIGURE 6: Parameter (Nd) ${ }^{1 / 2}$ Due to Voids in CW-i1316 (UK data)

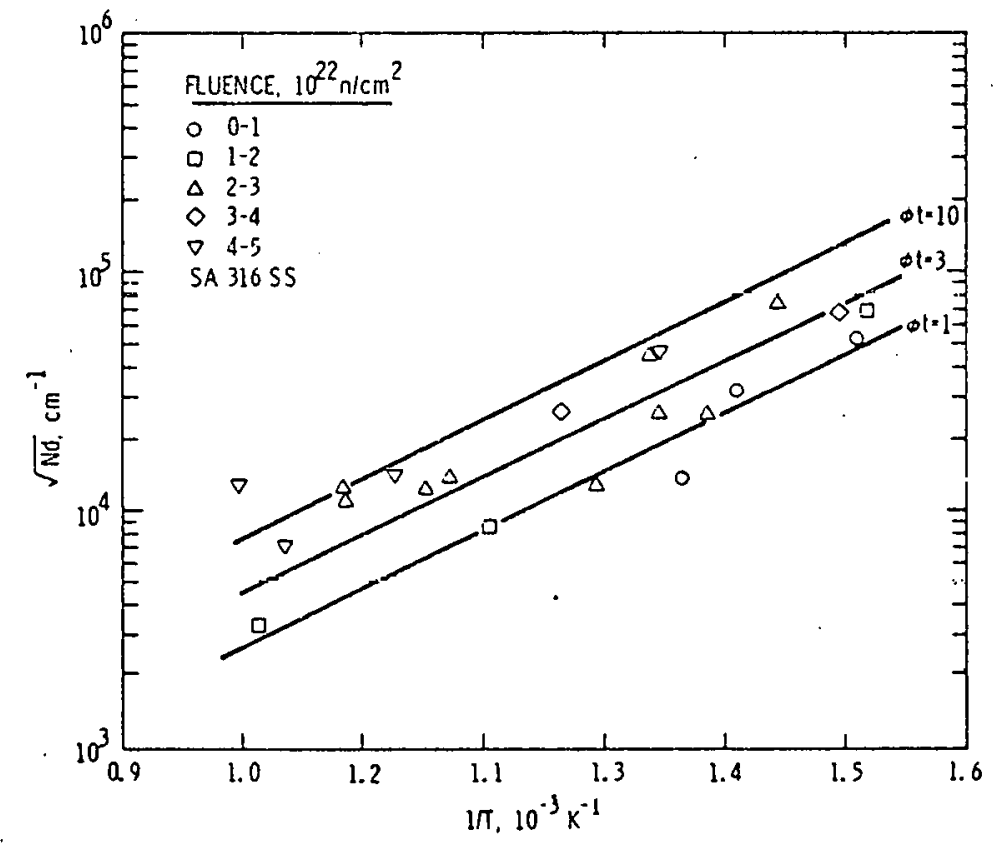

FIGURE 7: Paraneter (Hod ${ }^{1 / 2}$ Due to Voids in SA AISI 316 


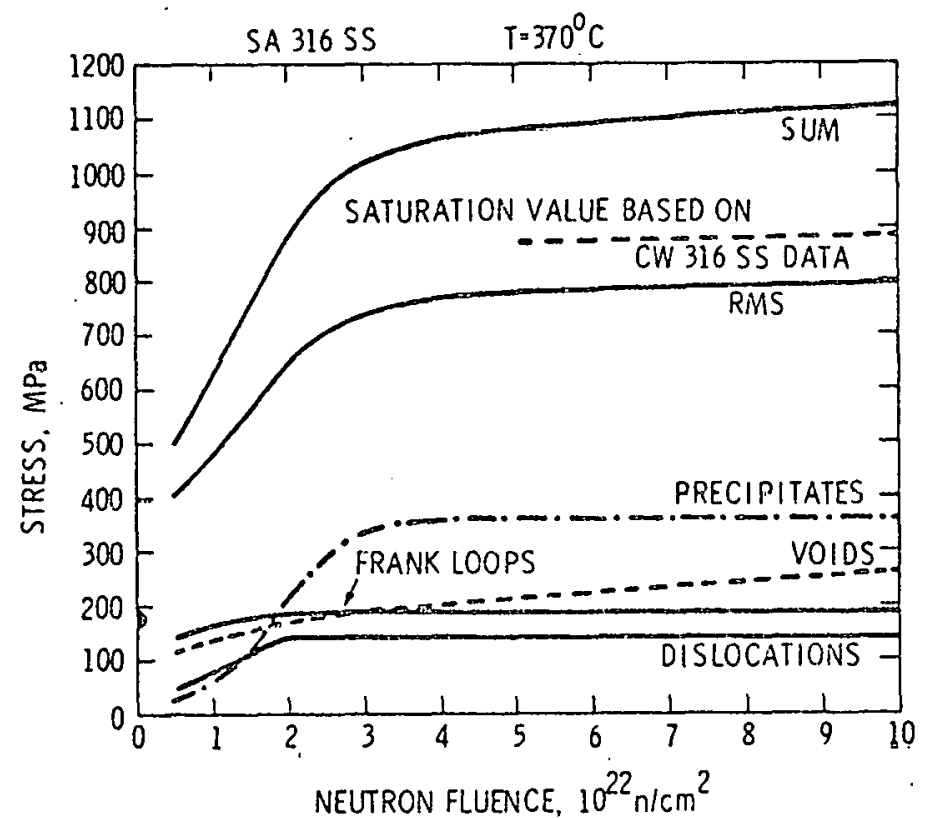

HEOL 8004-124.11

FIGURE 8a: Calculated Yield Strengths for SA AISI 316 for a

Test Temperature and Irradiation Temperature of $370^{\circ} \mathrm{C}$.

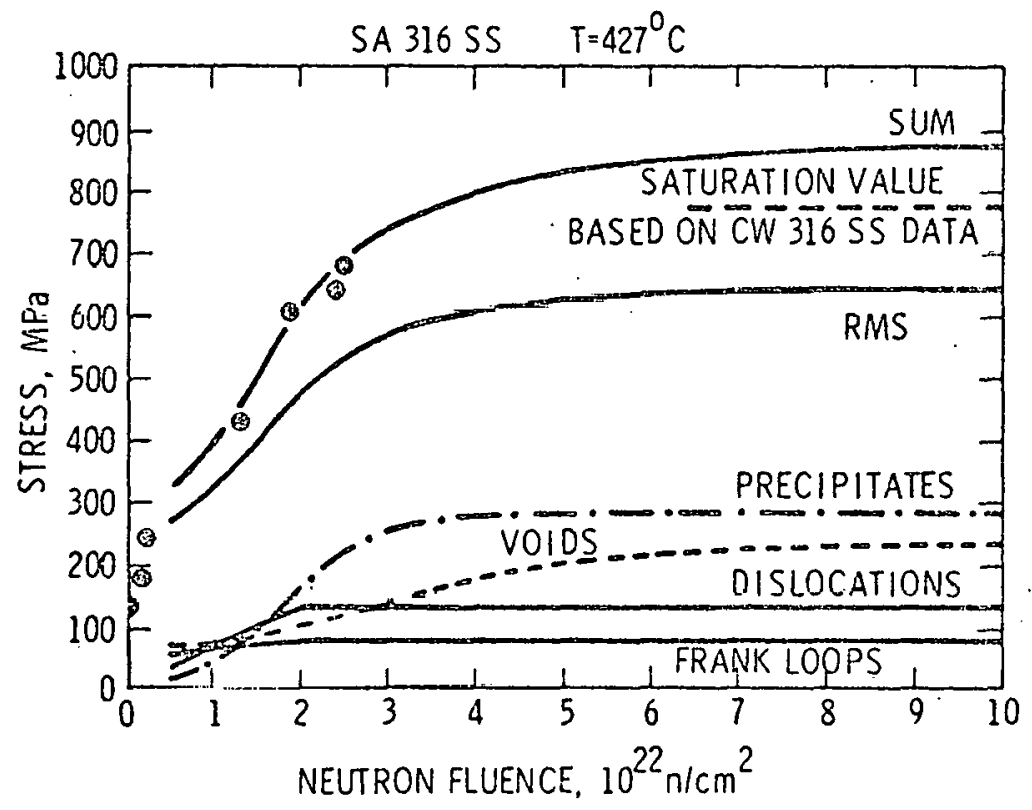

HEDL $8004-124: 10$

FIGURE 3b: Calculated Yield Strengths for SA AISI 310 for a

Test Temperature and Irradiation Temperature of $427^{\circ} \mathrm{C}$ 


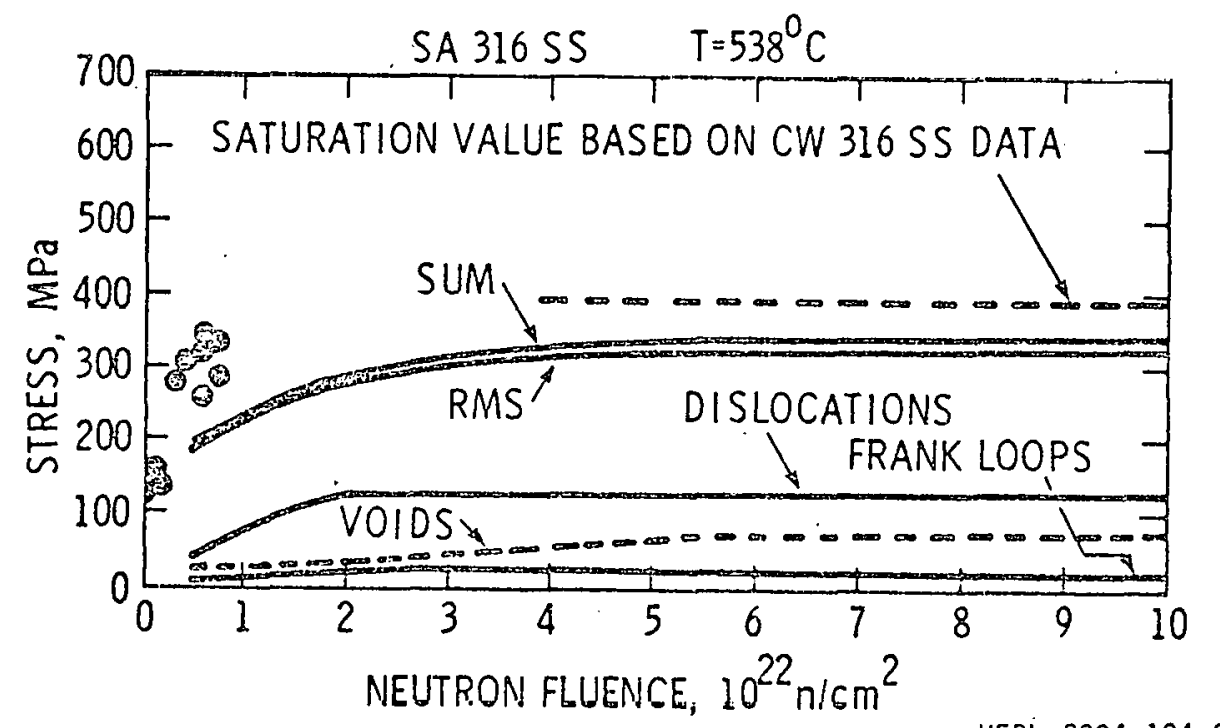

HEDL $8004-124.9$

FIGURE 8C: Calculated Yield Strengths for SAAISI 316 for a Test Temperature and Irradiation Temperature of $538^{\circ} \mathrm{C}$ :

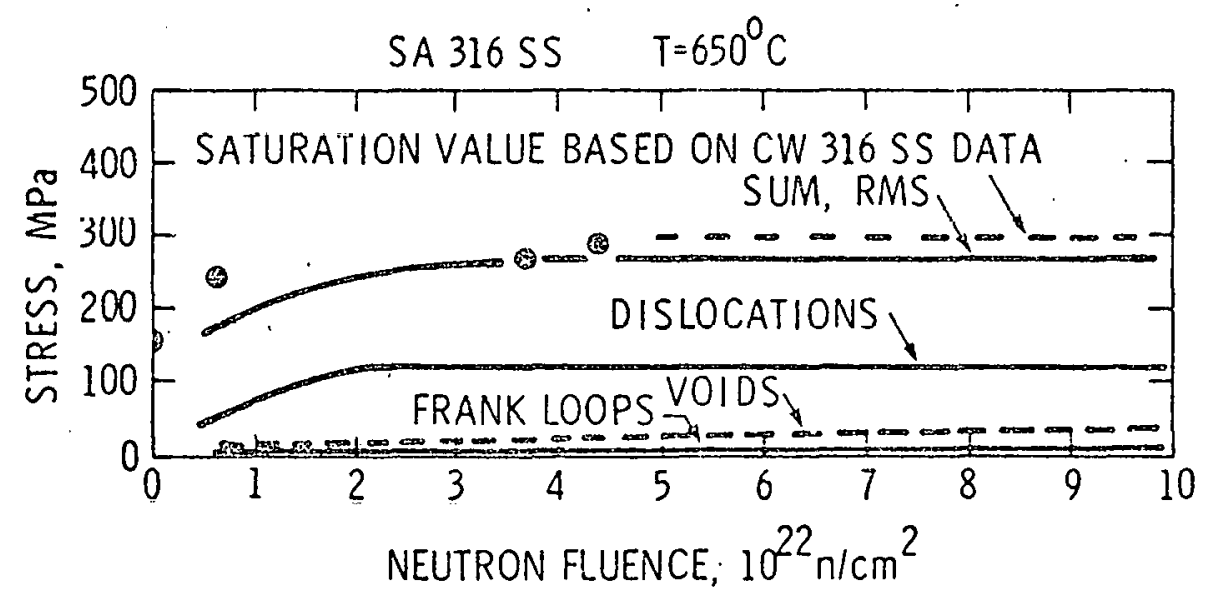

FIGURE 8d: Calculated Vieid Strengths for SA AISI 316 for a

Test Temoerature and Irradiation Temperature of $650^{\circ} \mathrm{C}$ 


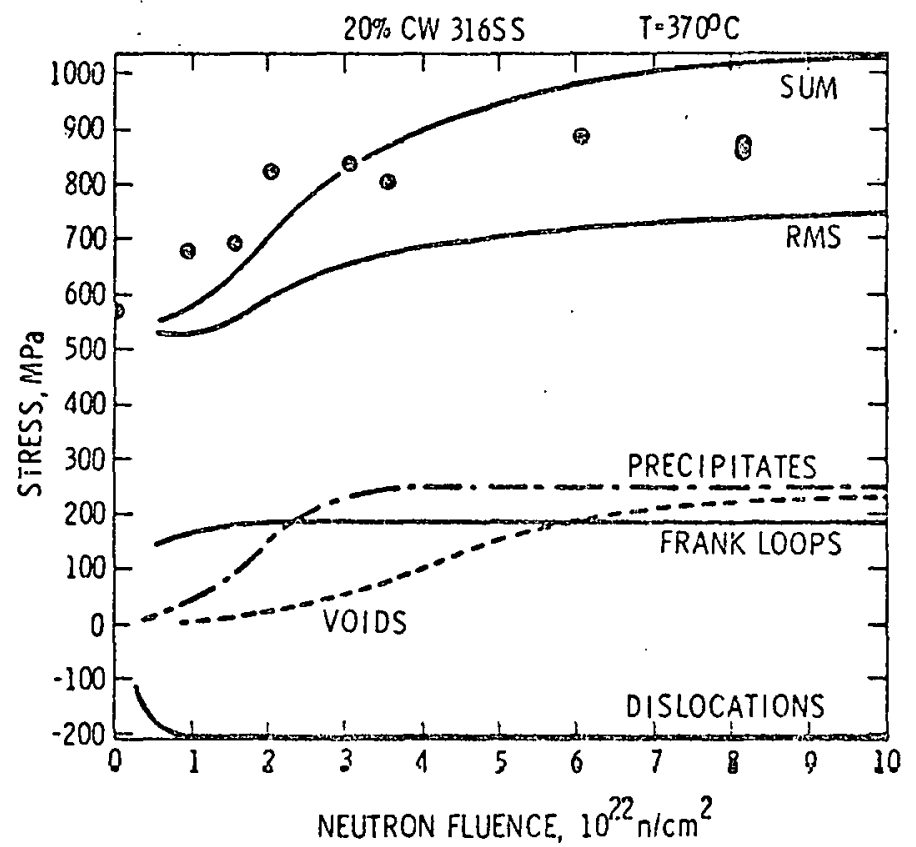

HEDL $8004-124.16$

FIGURE 9a: Calculated Yield Strengths for 20\% CW AISI 316 for

a Test Temperature and Irradiation Temperature of $370^{\circ} \mathrm{C}$.

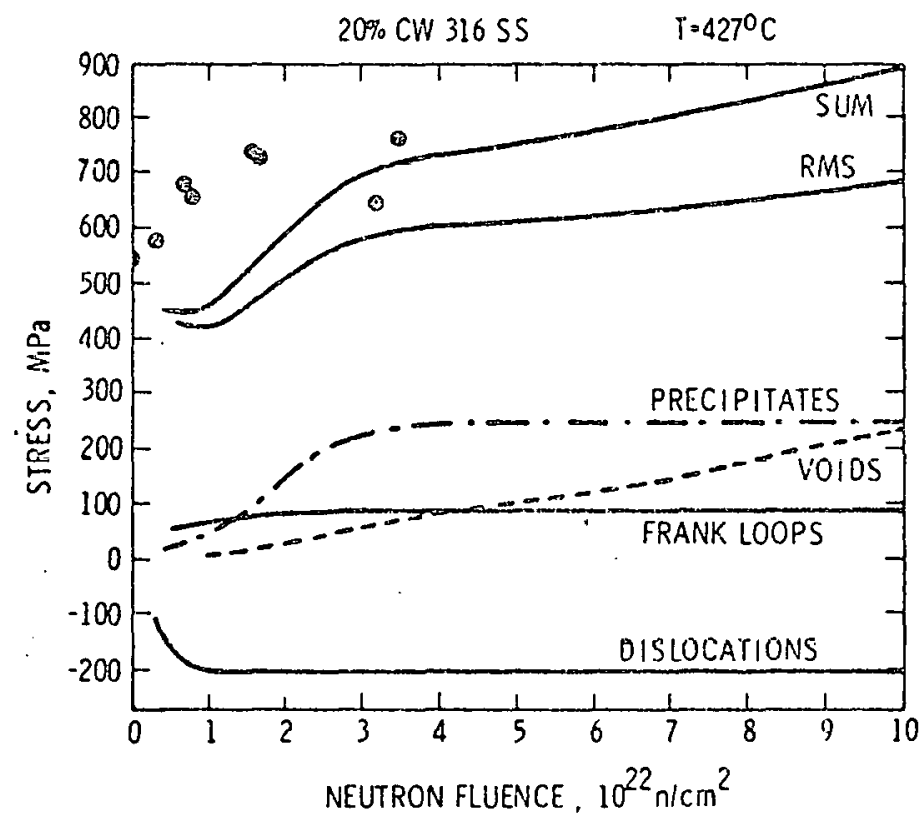

HEDI. $3004-124,15$

FIGURE 9b: Calculated Yield Strengths for 20\% CWAISI 316 for

a Test Temperature and Irradiation Temperature of $427^{\circ} \mathrm{C}$. 


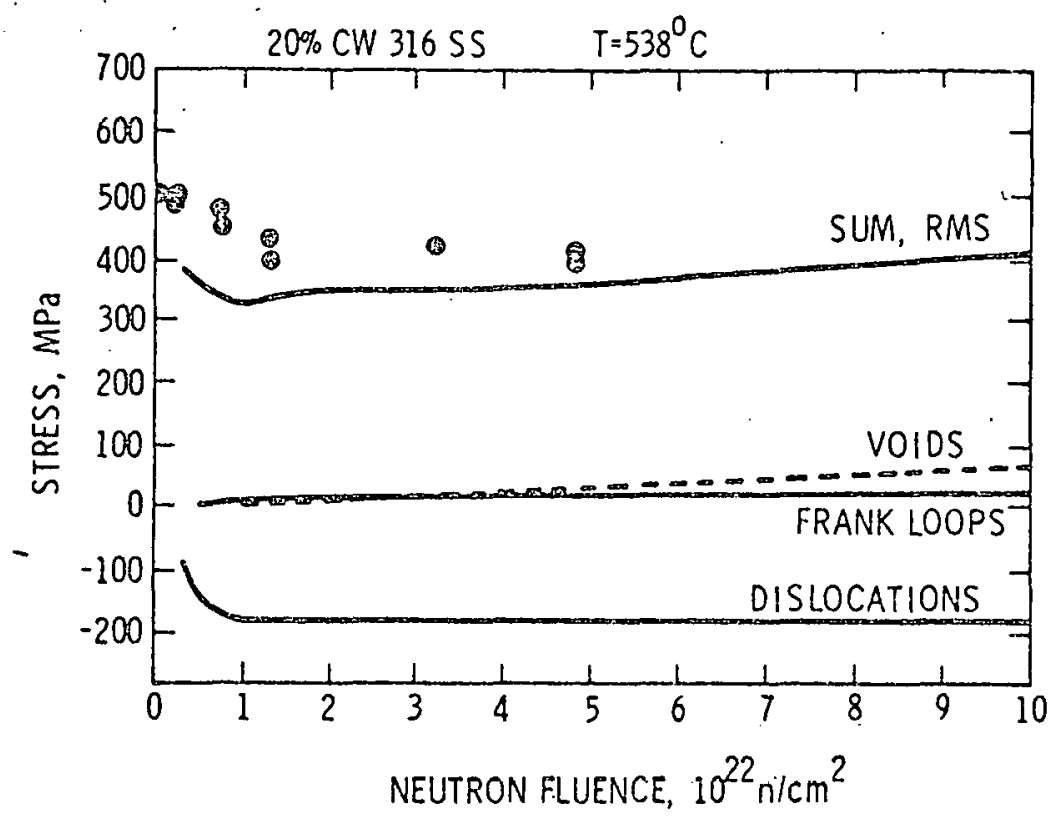

HEDL $8004-124.12$

FIGURE 9c: Calculated Yield Strengths for 20: CW AISI 316 for a Test Temperature and Irradiation Temperature of $538^{\circ} \mathrm{C}$.

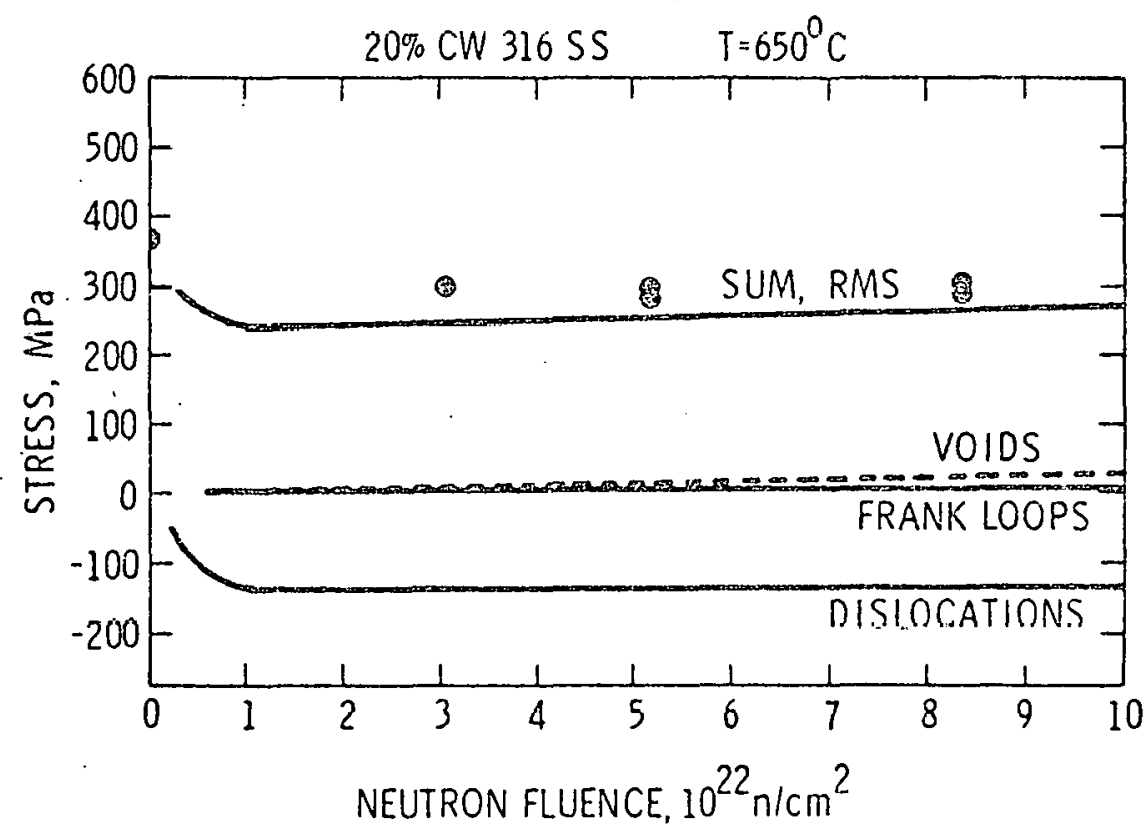

HEDL $8004-124.13$

FIGURE 9d: Calculated Yield Strengths for $20 \%$ C. N AISI 315 for

a Test Temperature and Irradiation Temperature of $650^{\circ} \mathrm{C}$. 


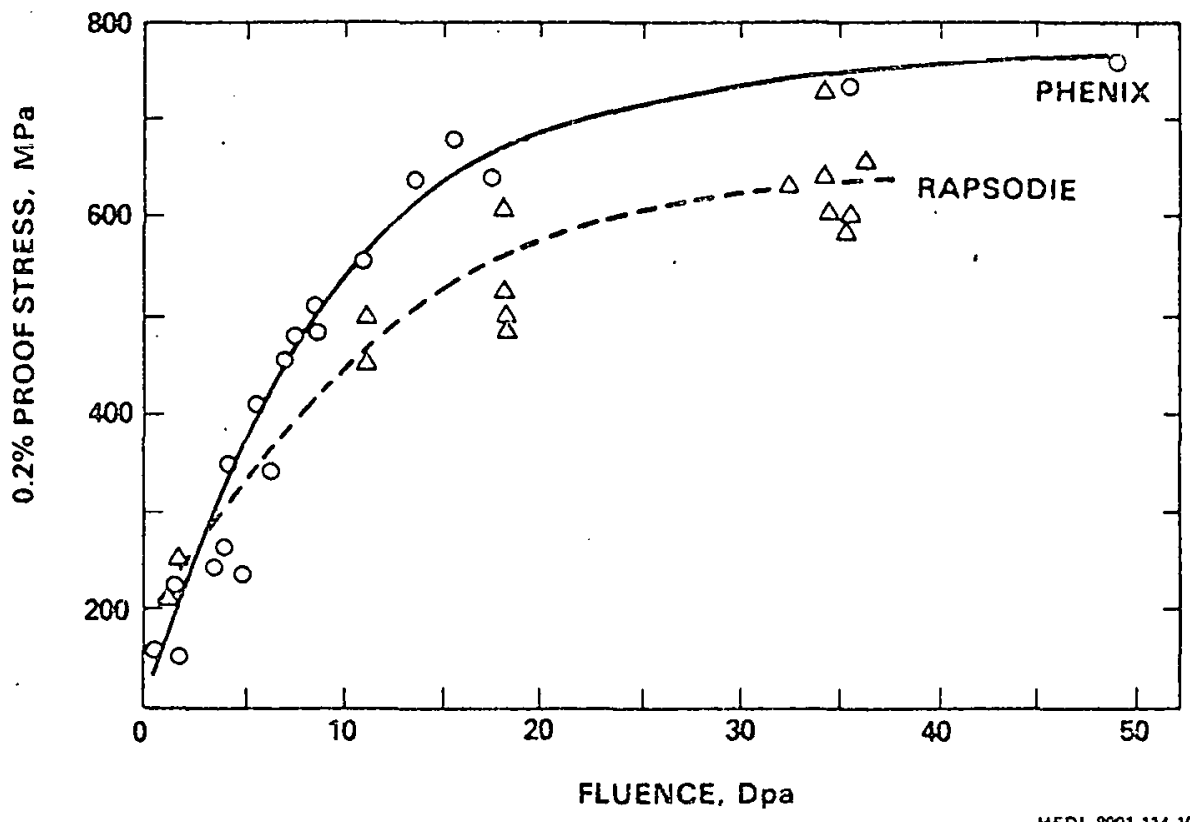

FIGURE 10: Comparison of the Yield strength of $S A 316 \mathrm{C}$.

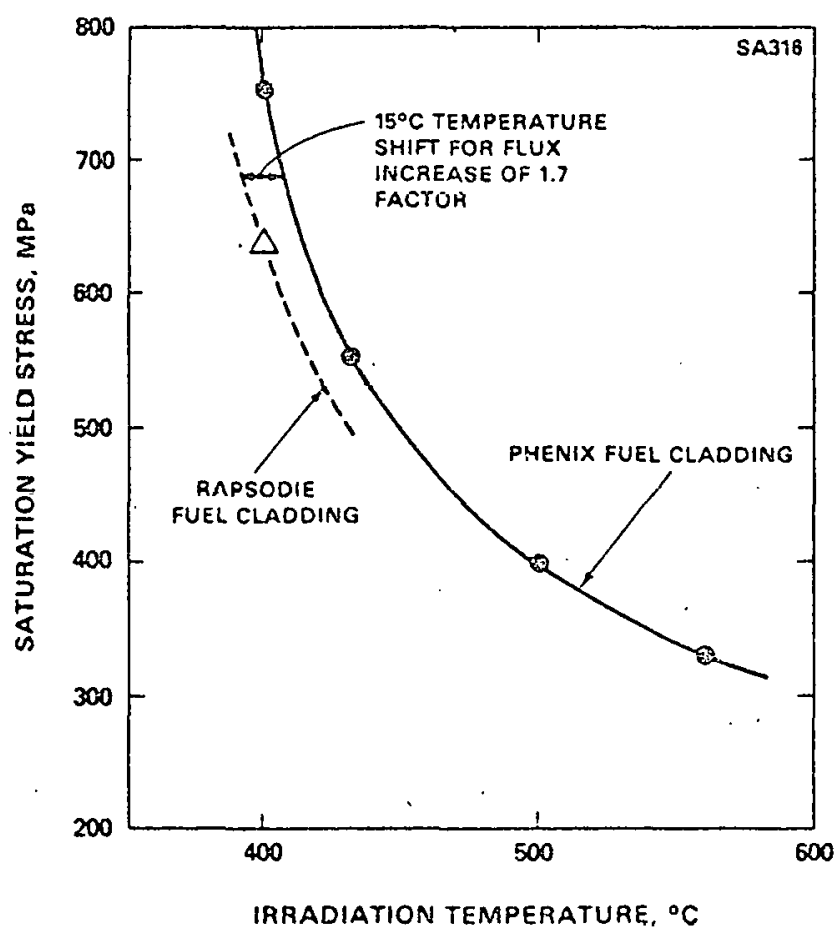

FIGURE 11: Temperature Shift of Saturation yield Strength of SA 316 Irradiated in Phenix and Rapsodie. 